\title{
Antiacne Compound from the Methanolic Extract of Hyptis (Hyptis capitata) Roots
}

\author{
Rahmini ${ }^{1}$ Irawan Wijaya Kusuma ${ }^{1, *}$ Cita Tri Murni Andayati ${ }^{2}$ Dedi Satria ${ }^{3}$ \\ Yhiya Amen ${ }^{4}$ Kuniyoshi Shimizu ${ }^{3}$ \\ ${ }^{1}$ Faculty of Forestry, Mulawarman University, Jl. Ki Hajar Dewantara, Samarinda, Indonesia \\ ${ }^{2}$ Faculty of Mathematic and Natural Science, Mulawarman University \\ ${ }^{3}$ Department of Agri-environmental Sciences, Kyushu University, Japan \\ ${ }^{4}$ Department of Pharmacognosy, Mansoura University, Egypt \\ *Corresponding author. Email: kusuma_iw@yahoo.com
}

\begin{abstract}
In the search of the antiacne agent from tropical medicinal plants, the methanolic extract of Hyptis capitata root was subjected to antiacne assay guided isolation of active compound. Extraction was conducted by maceration using methanol. The methanol extract was separated by column chromatography assisted by thin-layer chromatography to obtain active compounds. Antiacne activity against Propionibacterium acnes was analyzed using agar diffusion method at a concentration of $200 \mu \mathrm{g} /$ well with chloramphenicol as a positive control. Column chromatography of methanol extract gave five active fractions, in which fractions $\mathrm{AH} 1$ and $\mathrm{AH} 2$ to be the strongest by $85 \%$ and $82 \%$ inhibition respectively. Fraction AH1 was then chromatographed on silica gel column to obtain 16 subfractions. The active fractions isolated from $H$. capitata have the potential to be developed as a natural antiacne. Further purification, identification, and characterization of the active compounds would be our priority in future studies.
\end{abstract}

Keywords: Antiacnce, Methanolic extract, Hyptis capitata, Maceration

\section{INTRODUCTION}

Infection diseases pose a serious health concern worldwide. One of them is an infection caused by Propionibacterium acnes. $P$. acnes is an anaerobic pathogenic inhabitant of human skin and plays an essential role in acne's pathogenesis. $P$. acnes produces many putative virulence factors and causes disease by bacterial seeding, modification and manipulation of the host immune response, and biofilm formation [1]. It acts as an immunostimulator by producing enzymes such as lipases and proteases, which are involved in developing the inflammatory process [2]. Several treatments have been introduced to decrease the esthetic and psychological problems caused by acne. One of the treatments is providing antibiotics that can reduce acne, but excessive use can cause bacterial resistance to antibiotics to reduce the benefits. Therefore the search for new drugs is needed to avoid increasing the number of antibiotic resistance.
On the other hand, medicinal plants are a good source of natural products that may have the potential as antibacterial activity. One medicinal that local people in Indonesia have long used is Hyptis capitata. Hyptis capitata is a tropical herb of the family Lamiaceae. Local people in Kalimantan traditionally use the plant to treat various illnesses. They use leaves to prevent infection of external wounds and the roots as an antidote to food poisoning-moreover, the Taiwanese use the plant to treat colds, fever, and asthma. The community in the Rangamati district of Bangladesh treats snakebite by drinking the leaf juice of $H$. capitata [3]. Previous investigation of the leaves of $H$. capitata revealed the presence of alkaloids, flavonoids, terpenoids, fatty acids, and phenolic compounds [4]. Compounds 2,3-di (3',4'-methylenedioxybenzyl)-2-buten-4-olide, a lignan with a y-butenolide structure and lo-epiolguine, a 5,6dihydro-a-pyrone, stigmasterol, S-hydroxy-4',7dimethoxyflavone (apigenin-4',7-dimethyl ether), oleanolic, ursolic, and rosmarinic acids also have been isolated from $H$. capitata $[5,6]$. The root of $H$. capitata is reported to possess antioxidative properties and 
antimicrobial activity against Propionibacterium acnes and Candida albicans [7]. In contrast, active compounds from the roots of $H$. capitata have not been reported. Based on the previous screening experiments for $H$. capitata, this study aimed to isolate and identify the active compounds from $\mathrm{H}$. capitata roots as antibacterial agents against Propionibacterium acnes.

\section{MATERIALS AND METHODS}

\subsection{Plant Materials}

The leaves of $H$. capitata were collected from Samarinda, East Kalimantan, Indonesia, and authenticated by the Laboratory of Forest Dendrology, Faculty of Forestry, Mulawarman University, Indonesia. The plant roots were cut off and washed with tap water and dried at room temperature for a week, then pulverized to a fine powder using an electric hammer mill.

\subsection{Chemicals and Drugs}

Methanol, n-Hexane, ethyl acetate, acetone, silica gel, agar powder, alcohol, D-glucose, chloramphenicol, Dragendorff solution, ferric ferrocyanide reagent, vanillin, ammonia, and sulfuric acid were purchased from a chemical supplier.

\subsection{Extraction and Fractionation}

The powdered material (300 g) was macerated with methanol for $48 \mathrm{~h}$ with occasional mechanical shaking at room temperature. At the end of $48 \mathrm{~h}$, the mixture was filtered using filter paper, and the filtrate was then concentrated under vacuum using a rotary vacuum evaporator to obtain the crude extract. The methanol extract was further fractionated by column chromatography on silica gel, eluting $300 \mathrm{~mL}$ each of ethyl acetate : n-hexane mixture in ratios of $0: 10,1: 9$, $2: 8,3: 7,4: 6,5: 5,6: 4,7: 3,8: 2,1: 9$ and 10:0. The filtrates were collected in the test tube and grouped based on a thin-layer chromatography profile. Fraction AH1 with the highest antiacne activity was separated by silica gel column chromatography with hexane to obtain an active compound with a single spot.

\subsection{Antibacterial Activity Assay}

The antibacterial activity against Propionibacterium acnes was determined by the agar diffusion method as previously reported [8], with slight modification. Nutrient agar media was poured into a sterile petri dish and inoculated with bacterial suspension. Wells of (7 $\mathrm{mm}$ ) were punched in the media using a sterile cork borer. The extracts were introduced into the wells $(20 \mu 1)$ in a concentration of $200 \mu \mathrm{g} / \mathrm{well}$. All the inoculated plates were incubated for $\pm 18-24 \mathrm{~h}$ at $37^{\circ} \mathrm{C}$. A standard
Chloramphenicol was used as a positive control. Antibacterial activity was determined by measuring the diameter of inhibition zone formed around the well.

\subsection{Phytochemical Analysis}

Phytochemical screening of the active fractions was carried out with standard test procedures described [9].

\subsection{Data Analysis}

All values obtained were expressed as means \pm standard deviation. The tests were calculated based on the average of three repetitions for then compared with the positive control and the negative controls so that it could be analyzed for the inhibition of the fractions was used and the comparison of each fraction.

\section{RESULT AND DISCUSSION}

The yield of methanolic extract was $23 \%$ w/w. Fractionation of the methanolic extract of $H$. capitata roots by column chromatography on silica gel yielded 20 fractions which then were tested their activity against Propionibacterium acnes. P. acnes is part of the natural skin and mucosal flora inhabiting the skin's sebaceous follicles, conjunctiva, oral cavity, intestinal tract, and external auditory canal [10]. The extraction and fractionation process was presented in Figure 1.

\section{H. capitata roots \\ (300 g)

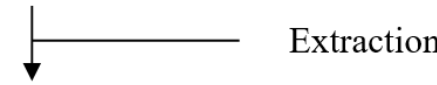 \\ Methanol extract \\ $(13,38 \mathrm{~g})$<smiles>[13CH3]</smiles> \\ Fractionation}

(TLC/Column chromatography)

$n$-Hexane : ethyl acetate : methanol

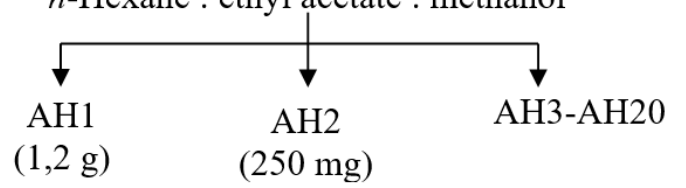

AH1 (1 - 16)

Figure 1 Extraction and fractionation process of $H$. capitata roots.

The in-vitro antibacterial activity against $P$. acnes was described in Figure 2. It was observed that fractions $\mathrm{AH} 1, \mathrm{AH} 2, \mathrm{AH} 3, \mathrm{AH} 7$, and $\mathrm{AH} 12$ have the ability to inhibit the growth of $P$. acnes at a concentration of 200 $\mu \mathrm{g} /$ well. Fraction $\mathrm{AH} 1$ and $\mathrm{AH} 2$ were found to be strongest by $85 \%$ and $82 \%$ inhibition, respectively. 


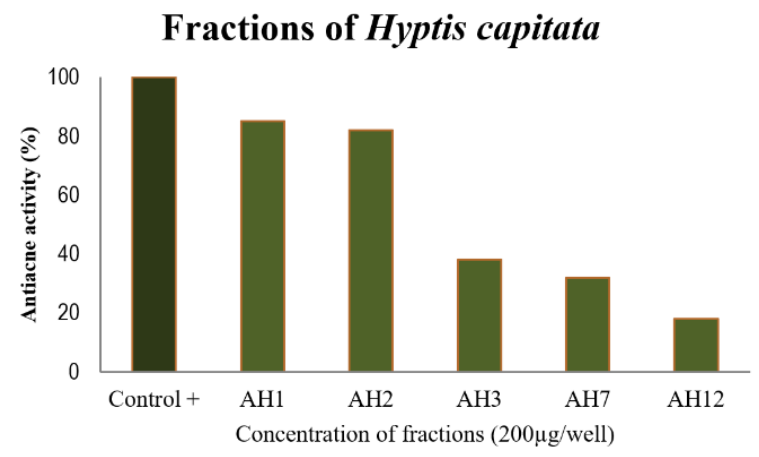

Figure 2 The histogram of antibacterial activity of fractions against $P$. acnes.

Fraction AH1 was then separated by column chromatography on silica gel and eluted by $100 \%$ nhexane to obtained 16 fractions. Fraction AH1-1 had orange needle-shaped crystals and showed a single spot that is purely based on the appearance of the thin layer chromatography profile in Figure 3.

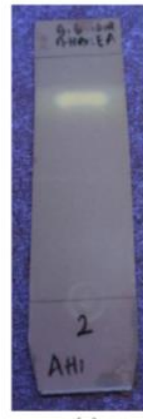

(a)

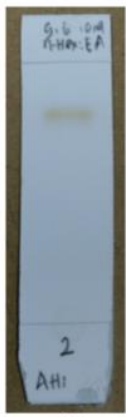

(b)

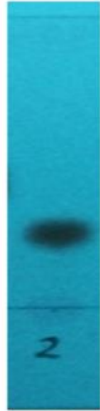

(c)

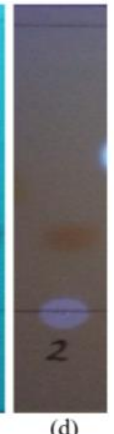

Normal-phase TLC Reverse-phase TLC

Note. (a) UV $254 \mathrm{~nm}$, (b) $\mathrm{H}_{2} \mathrm{SO}_{4} / \mathrm{MetOH}$, (c) UV $254 \mathrm{~nm}$, (d) UV $365 \mathrm{~nm}$

Figure 3 The appearance of thin layer chromatography profile.

Chemical compound identification through phytochemical analysis showed that fraction AH1-2 contains flavonoids. Flavonoids isolated from the plant extract that has antibacterial activity have been increasingly published. Crude extract from the plants has been screened for antibacterial activity by many researchers. Flavonoid-rich plant extracts from Hyptis, Chromolaena, Boesenbergia have been reported to possess antibacterial activity [7,11]. Many other phytochemical preparations with high flavonoid content have also been reported to exhibit antibacterial activity. It is evident from this study that, flavonoid compound isolated from $H$. capitata roots has the potential to be developed as an antibacterial agent against $P$. acnes.

\section{CONCLUSION}

Column chromatography of methanolic extract of $H$. capitata gave five active fractions, in which fractions
$\mathrm{AH} 1$ and $\mathrm{AH} 2$ have the highest inhibition of $85 \%$ and $82 \%$, respectively. The purification process of fraction AH1 yielded fraction $\mathrm{AH} 1-2$ that has a single spot and contains flavonoids. Flavonoids isolated from $H$. capitata have the potential to be developed as a natural antiacne. Further identification and characterization of the active compounds would be our priority in future studies.

\section{ACKNOWLEDGMENTS}

The authors are gratefully acknowledging the Directorate General of Research and Community Services, Ministry of Research, Technology and Higher Education, the Republic of Indonesia by the Competence-Based Research Grant (Contract no. 349/UN17.41/KL/2017. The support from Fitriani and Endang Suryanti of the Faculty of Forestry, Mulawarman University, during sample collection is gratefully acknowledged.

\section{REFERENCES}

[1] Y. Achermann, E.J.C. Goldstein, T. Coenye, M.E. Shirtliff, J. Asian Soc. Microbiol. 27, 2014, pp. $419-440$

[2] M. Toyoda, M. Morohashi, J. Med. Electron Microsc 34, 2001, pp. 29-40

[3] I. Tasannun, F.A. Ruba, B.U. Bhuiyan, K.M. Hossain, J. Khondokar, I. Malek, A.B.M.A. Bashar, M. Rahmatullah, American- Eurasian J. Sustain Agr. 9 (5), 2015, pp. 28-35

[4] D. Rupa, Y. C. Sulistyaningsih, Dorly, D. Ratnadewi, J. Biotropia 24 (2), 2017, 94-103

[5] G.T. Almtorp, A.C. Hazell, B.G. Torssell, Phytochemistry 30 (8), 1991, pp. 2753-2756

[6] T. Yamagishi, D. Zhang, J. Chang, D.R. McPhail, A.T. McPhail, K. Lee, Phytochemistry 27 (10), 1998, pp. 3213-3216

[7] I.W. Kusuma, Murdianto, E.T. Arung, Syafrizal, Y. Kim, J. Food Sci and Hum.Wellness. 3, 2014, pp. 191-196

[8] B. Singh, P.M. Sahu, M.K. Sharma, J. Phytomedicine 9,2002 , pp. 355-359

[9] J. Pascaline, M. Charles, C. Lukhoba, O. George, J. Ani and Plant Sci. 9 (3), 2011, pp. 1201-1210

[10] D. Saper, N. Capiro, M. Richard, L. Xinning, Curr. Rev. Mus. Med. 8, 2015, pp. 67-74

[11] A. Chahyadi, R. Hartati, K.R. Wirasutisna, Elfahmi, J. Proc. Chem. 13, 2014, pp. 13-37 